\title{
Article Review: Present Perspectives of Hyperthyroidism During Pregnancy
}

\author{
Meena S. Farman', Rana Hazim Hamoode ${ }^{2}$, Dalal A. Sattar ${ }^{3}$ \\ ${ }^{I}$ Instructor of Physiology, Department of Biology, College of Science, University of Anbar, Anbar, IRAQ, \\ ${ }^{2}$ Instructorof Physiology, Basic Science Department, Dentistry of College, University of Anbar, Anbar, IRAQ, \\ ${ }^{3}$ Instructor of Physiology, Department of Biology, College of Science, Mustansiriyah University, Baghdad, IRAQ
}

\begin{abstract}
Graves' disease causes inflammatory hyperthyroidism in around $80 \%$ of hyperthyroidism cases in women of reproductive age. The hormonal changes in the maternal immune system after birth may be linked to the production and expression of diabetes other than gestational and early-onset diabetes. As a result, in addition to hormonal influences, other anatomical modifications or abnormalities seen in the body during pregnancy will affect the pregnancy test. Thyroid hormones are critical for a woman's health and the commencement of her pregnancy. These hormones are essential for early development and play a crucial role in the fetus's continued growth after conception. Women with untreated or improperly controlled hyperthyroidism are more likely to have complications during pregnancy. Future diseases, particularly those that produce a large number of fetuses due to IUGRTH. The treatment of hyperthyroid pregnant women is extremely difficult, and medical staff engagement is required to guarantee that it is properly monitored and treated. Anti-thyroid drugs are commonly administered to pregnant women, and it is the medication of choice for the majority of them (ATDs). Despite the fact that both of these drugs are passed through the mother's bloodstream to the fetus, they are highly effective in the treatment of maternal hyperthyroidism. Nonetheless, they must exercise caution throughout the second half of pregnancy due to the risk of fetopathy. The most common side effect, except in the first trimesters from weeks 6 to 10, is fetal abnormalities; even with that proviso, the incidence of birth malformations is significant during the first trimester with the use of ATDs. The management of hyperthyroidism during pregnancy is divided into four areas that obstetricians are currently concerned about: Its aetiology, occurrence, correct identification, under treatment, complications, and actual or missed diagnosis and intervention, and lastly, the technique of dealing with the problem are all factors to consider.
\end{abstract}

Keywords: hyperthyroidism, disease occurrence, diagnosis, aetiology.

\section{Introduction}

In contrast to the thyroid-hypothyroidism, hyperthyroidism is associated with abnormally elevated amounts of thyroid hormone resulting from an enhanced production and secretion. In contrast,

\section{Corresponding author:}

\section{Meena S. Farman}

email is: meena.sabah@uoanbar.edu.iq, "hyperthyroidism" describes an excessive output ${ }^{[1]}$, whereas "hypothyroid" describes elevated thyroid hormone synthesis. Basing the care of those with hyperthyroidism on experience and evidence, what has been seen in prior studies is necessary to guarantee a minimises its effects and complications. Women of reproductive age who are or who may become pregnant face the following challenges: a greater risk of hyperthyroidism, or than younger women who are 
not, for the following reasons:

1) An aetiology and prevalence of overt or suspicious hyperthyroidism in pregnancy,

2) In the first trimester, the condition of hyperthyroidism is "abnormal or high thyroid stimulating hormone in the mother and the baby",

3) Without treatment, there can be symptoms of overt hypothyroidism as well as well as hyperthyroidism throughout breastfeeding,

4) In addition to seeing an increase in TSH levels during breastfeeding, treating overt hyperthyroidism is often increases the risk of miscarriage.

Increasing amounts the hormonal modifications in pregnancy complicate the understanding of thyroid tests and the results. While explicit (the presence of all three thyroid hormones, not just one) thyroid stimulating hormone (TSH) and elevated T3 (or T4) levels ${ }^{[2]}$ are common in euthyroid conditions (suppressed TSH and normal T3 and T4). Increase the study here considers how overt hyperthyroidism in pregnant women is typically is dealt with and recent thoughts on treating it.

\section{Hyperthyroidism during Pregnancy: Aetiology and Prevalence}

\section{Etiology of the thyroid disease}

Particular hyperthyroidism exists, and three distinct subtypes are Graves' disorder, multimonitor nodular, and single toxic adenoma. Many forms of hyperthyroidism present have a striking predominance of females. Still, there is a notable difference concerning the peak age of onset and how many of them there are compared to the other types (Figure 1). People with new-based, family-oriented classification and person subclassification for Graves' disease discovered that the new variant had a gradual occurrence up to a maximum age of 40 years $^{[3]}$. Which was stable from the individual to family sub classification, with the inclusion, before it became an overt form of hyperthyroid Graves' disease (Figure 1) and (toxic multinodiono cellular and solitary carcinoma were seldom seen in children and were more common in older individuals. These diseases increased in frequency specifically for toxic nodular goitre was more common, with age, as is typical of tox (adnexusedl) multunoide syndromes in older adults.

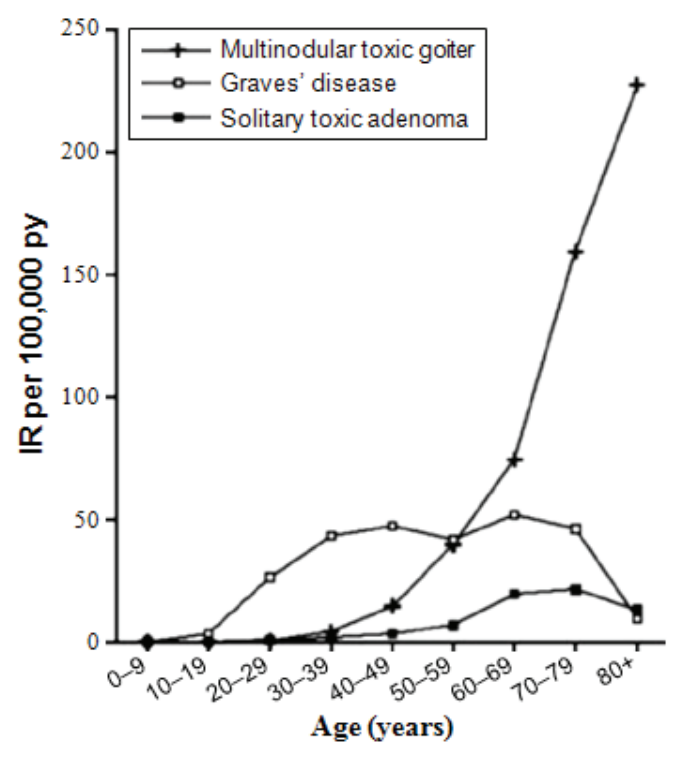

Figure 1: For the most popular forms of hyperthyroidism in Iraq, age-specific IR per 100,000 py 
Graves' disease is an infectious disorder in which the thyroid gland is targeted by autoantibodies and has an elevated thyroid hormone production. In all cases (95\% of those) have abnormal thyroid stimulating antibodies (TRA) in the blood, the condition caused by an overactive pituitary gland called hyperthyroidism ${ }^{[4]}$. More than one nodule can be found in a woman's thyroid gland, and no autonomous hyperthyroidism usually do not result. However, autoimmune hyperthyroidism, there is a condition where thyroid hormone synthesis occurs independently of TSH. It's also assumed that low iodine is usually causing such an enlargement of the thyroid gland later in life.

\section{Hyperthyroidism in pregnancy: what is the rate of occurrence?}

Any pregnant women with Graves' disease would go on to the ER after their thyroid has been examined, and this is the key kind of hyperthyroidism the gets overt. Though, other kinds of thyrotoxic states can be discovered in the first trimester of pregnancy and must be differentiated from the hyperthyroidism found in Graves' disease ${ }^{[5]}$. Thoroughly entangled physiological shifts in the pregnant effect on the thyroid during the early stages of pregnancy, there is a dramatic rise in human chorionic growth hormone (hCG), leading to a surge in thyroid hormone levels. The hCG is a glycoprotein synthesised in the placenta, which influences the TSH receptor because of structural similarity. Gestational hyperthyroidism is a non-autoimmune condition that often lasts in the first trimester of pregnancy and is attributed to high levels of human chorionic gonadotropin. In gestational hyperthyroid, the more common Graves' disease is often manifested ${ }^{[6]}$ as hyperemesis gravidus, although it is impossible to tell apart from hyperemesis syndrome in certain cases. As tested by a radioactive dye, the existence of TRAb confirms the "diagnosis of Graves' disease".

Expand the prevalence of "Graves' disease" may be increased before and after birth. One of the two dominant functions of pregnancy is the profound immunologic improvements in the maternal system, which often appear to increase TSH levels. A particularly high amount of oestrogen makes thyroid hormone output go up, leading to a spike in total T3 and total T4.

Furthermore, it is essential to follow certain hormonal modifications while attempting to determine the serum hormone concentrations of pregnant people. There is a significant increase of thyroxinebinding globulin content during breastfeeding, resulting in free thyroid suppression. An immune recovery then accompanies this after the baby is born $^{[7]}$. Since these gene mutations affect the initiation of autoimmunity, they might cause damage to an individual's immune system (Figure 2). What was discovered in a Danish cohort of 403,958 women's total populations (reported in medical literature as temporary hyperthyroidism or thyroiditis) turned out to be the case that women suffered from the condition early in pregnancy experienced incremental changes and continued worsening. Those who survived that time had given birth were more susceptible to its after giving birth, presumably because the population is no longer immune to the disorder ${ }^{[8]}$, as we assume (Figure 2). It is possible that individuals predisposed to Graves' disease could be driven by hCG-triggered increases in the output of thyroid hormone during the early stages of pregnancy. However, Graves' disease that occurred before conception could become more complicated in the early stages of pregnancy. 


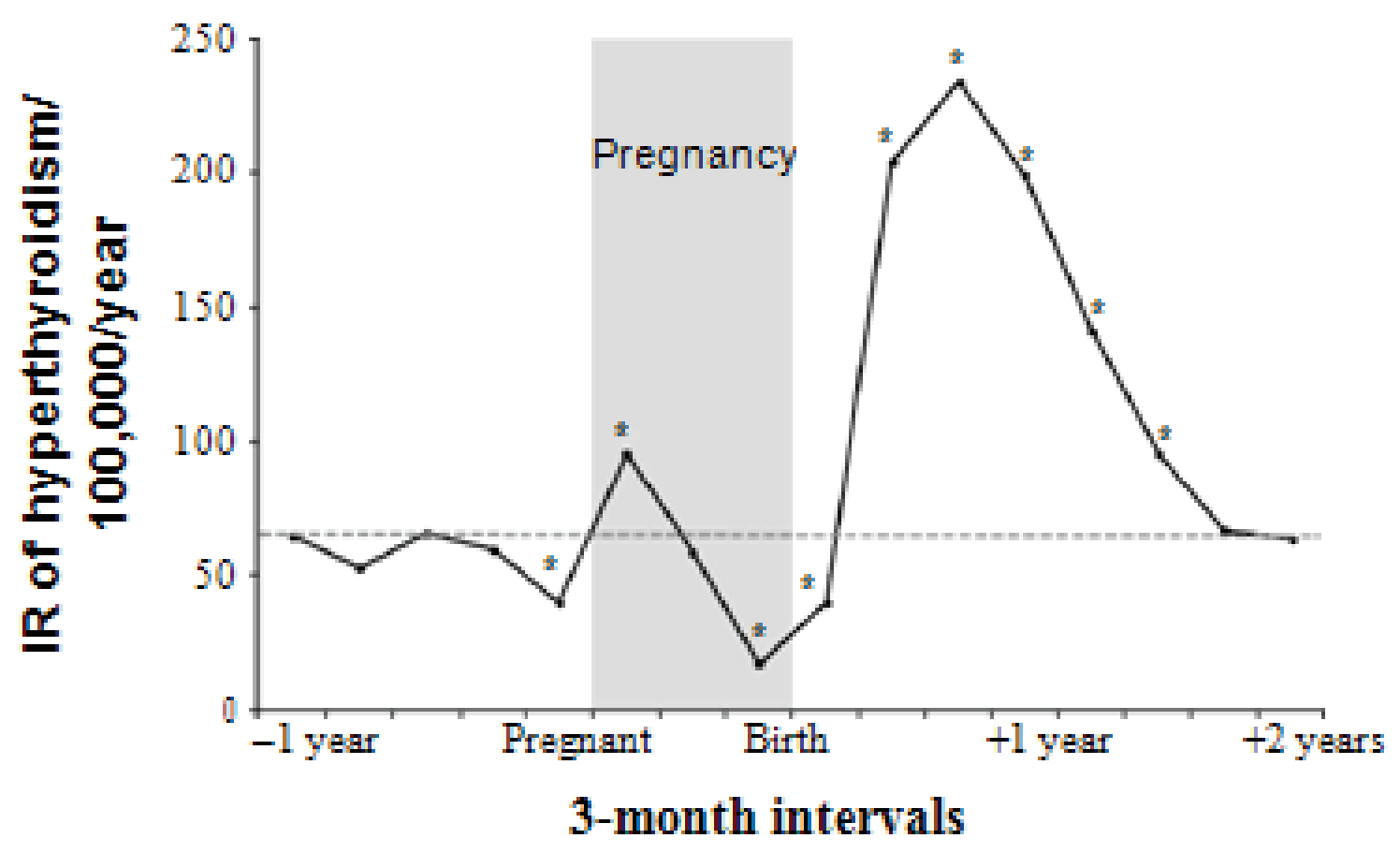

Figure 2: A live-birth child is born at three months before and during the first pregnancy after IR of maternal hyperthyroidism.

Abbreviation: IR, incidence rate.

Pregnancy has an increased risk of hyperthyroidism

Disruption due to a change in thyroid hormone levels

As the physician may evaluate for apparent hyperthyroidism by checking a suppressed TSH and elevated T3 and T4 levels, the underlying condition is hyperthyroidism. On the other hand, new travel sizes, the physiological changes that take place during pregnancy can interfere with the perception of thyroid tests ${ }^{[9]}$. An increase of thyroxine levels is another way the body adapts to elevated levels of hCG in the early stages of pregnancy by producing more thyroid hormone and suppressing the TSH. The form-3-deiodinase enzyme, which is used to type and research placental hormone synthesis in many countries, is also elevated in the placenta ${ }^{[10-11]}$. The use of ultrafiltration or dialysis for the initial calculation of free thyroid hormone concentrations is technically complicated. However, it can be done using protein precipitation or chemical treatments to separate the protein-bound component. While in routine analyses, the assays are used. The researchers use indirect measures that estimate total hormone concentration to quantify free hormone, not just the free hormone measures. In addition, techniques used to calculate free thyroid hormone concentrations vary greatly.

It is also important to consider that a woman's thyroid function will vary with each pregnancy. During the first and last trimesters have been suggested, particularly those targeting the second and third trimesters. Expand; However, it might be inaccurate to say that there are little physiological improvements in the first trimester of pregnancy, as this term might be insufficient to fully capture all that is taking place ${ }^{[12]}$. During early pregnancy, the Dimension Vista assay (Eschborn, Germany) shows lower and upper limits of thyroid stimulating 
hormone (TSH) concentrations (measured as in Figure 3) which were matched to healthy Danish women, respectively. When does a non pregenergetic fluid not constitute true nutrition? This information is provided by the producer, which is highlighted with dotted horizontal lines. In adults without pregnancy, a diagnosis of hyperthyroidism will be provided if the TSH level was lower than $0.358 \mathrm{mU} / \mathrm{L}$ whereas the fT level was higher than $18 \mathrm{pmol} / \mathrm{L}$. The study demonstrated that, as shown in Figure 3, the overt hyperthyroid classification criteria did not correctly identify all pregnant people ${ }^{[13]}$. The lower reference limit for Thyroid Stimulating Hormone was higher in early pregnancy and subsequently lower in the second trimester. Whereas for people who are not pregnant, the upper reference level was less variable, but with more prominent later in pregnancy, for an increasing variation of 0-14 weeks, the lower reference level in the narrowing earlier on the scale was consistent from week 9 to week 12. Preferably, these are set as weekspecific ranges during the first trimester to account for changes in the thyroid during this period of pregnancy.
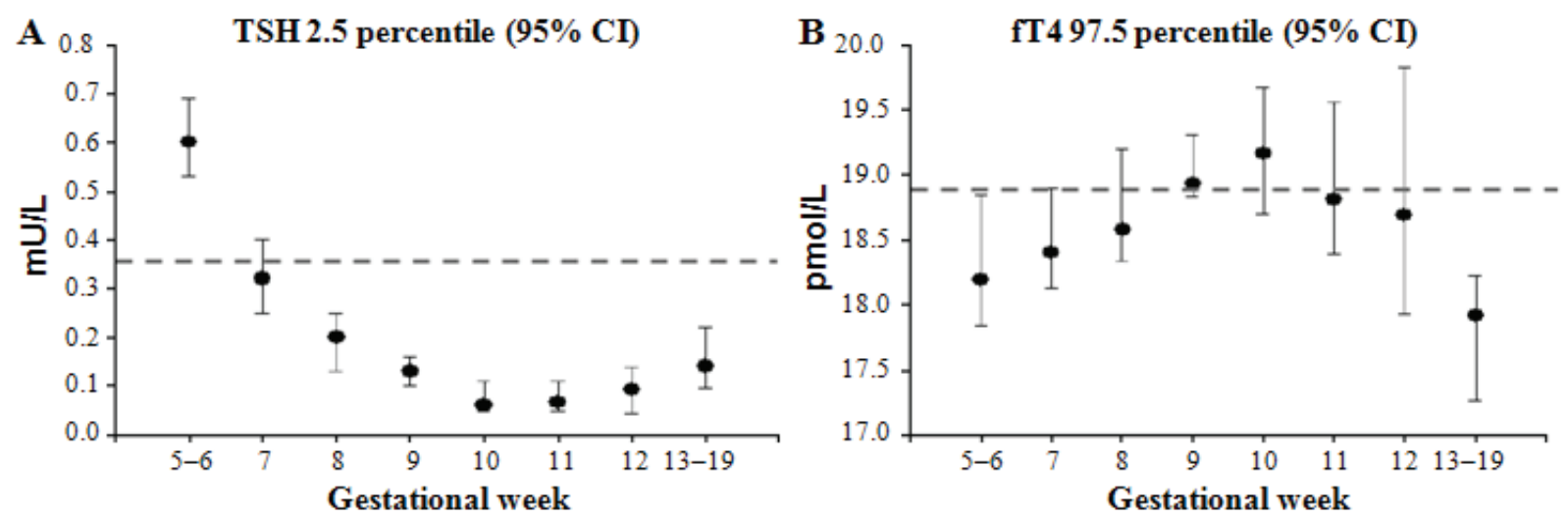

Figure 3: The diagnosis of hyperthyroidism in early pregnancy for the automatic immunoassay Dimension Vista (Siemens) was used to establish reference limits.

\section{Pregnancy-related untreated hyperthyroidism}

\section{Unassisted reproduction}

Delaying the diagnosis of hyperthyroidism in pregnant women can cause many issues, such as the dangers of fetal development, maternal and neonpregnancy health. A type of overt hyperthyroidism is recognised as a serious clinical issue ${ }^{[14]}$. Laboratory and control measures implemented Expand While the relationship between subclinical hyperthyroidism and pregnancy problems has not been established, research has not uncovered it either.

Thyroid hormones are essential for the growth of the fetal during gestation. Normal levels of thyroid hormone are required during pregnancy in the mother and during delivery, which results in the normal levels of thyroid receptor function in the fetal. Hypothyroidism can raise the risk of early and late pregnancy failure. There is a connection between maternal hyperthyroidism and early childbirth and an increased chance of delivering ${ }^{[15]}$ underweight infants, and $\mathrm{m}$ is of adverse effects for the female pregnancy, such as preterm labour and preeclampsia and ea syndrome biliary or maternal heart failure.

Your fetal already has thyrotropic hormone receptors in the fetal brain, and these help determine the function of the neurological system of the unborn child. But during the second half of birth, the fetal 
thyroid gland's capacity to produce thyroid hormones expands. Thyroid production increases somewhat in the second half of the pregnancy, but the fetal is more critical for the second half ${ }^{[16]}$. Experimental data on high levels of maternal hormone disrupt normal brain function in the fetus, which was proven in the general community. As well as in an estimated one group, have shown Heller's research also shown out in epidemiological trials that an excess of maternal thyroid hormone is correlated with brain growth problems in the infant.

The risks of both hyperthyroidism and attention deficit hyperactivity disorder and later in life and undetected thyroid hormone levels during pregnancy is elevated in the children of children whose mothers were first diagnosed with hyperthyroidism during pregnancy (having never had any previous medical treatment) were shown in a national Danish survey to be greatest in that group (this is one that first-time treatment with medical treatment and, presumably, pregnancy). It is suggested that the fetus's thyroid conditions $^{[17]}$ can result in subtle, systemic, or functional alterations throughout the development of the early fetal brain development may have a lasting impact on the adult disease status 27 The existing theory doesn't provide for much more research, so further experiments, including studies measuring the maternal thyroid gland during pregnancy, are required to establish the relationship between thyroid function and pregnancy.

\section{Cure of Hyperthyroidism during Pregnancy}

\section{Premature pregnancy}

To avoid maternal and infant risks, overt hyperthyroidism should be properly handled. Physiological hCG symptoms may increase at the level but there needs to be no attempt to treat those before 12-15 weeks gestation, since it is more likely than the other forms of hyperthyroidism
(ATDs). There is no evidence that treating this acute physiologic hyperthyroidism with any TCD treatment can improve the chance of a successful pregnancy. The infant was treated for (via a course of diet and rehydration) and tested (every two to three weeks) for excessive thirst in order to provide ${ }^{[18]}$ an accurate assessment of thyroid activity every two to three weeks over the course of their care.

ATD is the preferred therapy for overt hyperthyroidism in pregnant people. 5 Pregnancy cannot be treated with radioiodine. Thyroidectomy, ideally in the second trimester of pregnancy, is an alternative therapy if ATDs are not accepted.

Thioamides are substances that block the thyroid gland from developing thyroid hormone from being produced $^{[19-20]}$. Several of the medications available include methiomylmerchloride (Methimazol), propylamine, and the prodrugs CMZ, MMI, and propylthazin, respectively (PTU). Research suggests that the drugs work in comparable ways as treating hyperthyroidism. By their full development into the foetus, they all occupy the placenta, leading to hypothyroidism in late pregnancy (see the segment on "Late pregnancy"). However, the main issue when using these medications in early infancy is the possibility of birth defects.

Before the pregnancy, it was discovered that the exposure to At doses during the first three trimesters of the pregnancy was connected with birth defects ${ }^{[21]}$, Eleven of the two of the eleven moms who had given birth to a child with a birth defect on the scalp were helped to increase their birth weight with MMI, according to a research done in a 2014. In addition, two further instances of birth defects were discovered in babies born to mothers who were administered MMI or CMZ while pregnant ${ }^{[22-23]}$. airway of delivery with cleft lip and oesophagus, oesophagus, and upperair delivery defects, as well as other malformations is considered to be components of the population 
syndromes, and so resulted in the discovery of a community complex OME, pyloric septal and duodisc and GI tracts ${ }^{[24]}$, and oesophagus with cleft duodental and pyloric duodental intral CoAte, pylor orupperways distribution defects, as well. since the 1990s, results from clinic and population-based studies have confirmed the apparent risk of birth defects seen in these latest clinical research studies Japan and Iraq have conducted studies finding that indicate that $\mathrm{MMI} / \mathrm{CM}$ causes high-affected children to have an increased risk of malformations in pregnancy ${ }^{[25]}$. Additionally, the birth defects affected different organ systems, as seen in the upper panel of Figure 4, were found to be related to environmental factors. The embryopathy previously described may also (besides) show up in the general population; it is supported by a few of these studies as well.

Additionally, a Danish research demonstrated that babies who were treated with PTH had an increased likelihood of congenital abnormalities ${ }^{[26]}$. While the types of birth defects following methotrexatehinamide and zincirodate exposure were similar, the type of birth defects found in these two examples was distinctly different and less harmful (Figure 4). Along with the a preauricular sinus, kidney defect, sacral groove, and nephropsydrops, there were discovered in the face and back, as well as the urinary tract disorders ${ }^{[27-28]}$. More than two-thirds of cases have been treated surgically, with respect to their seriousness of their illness.

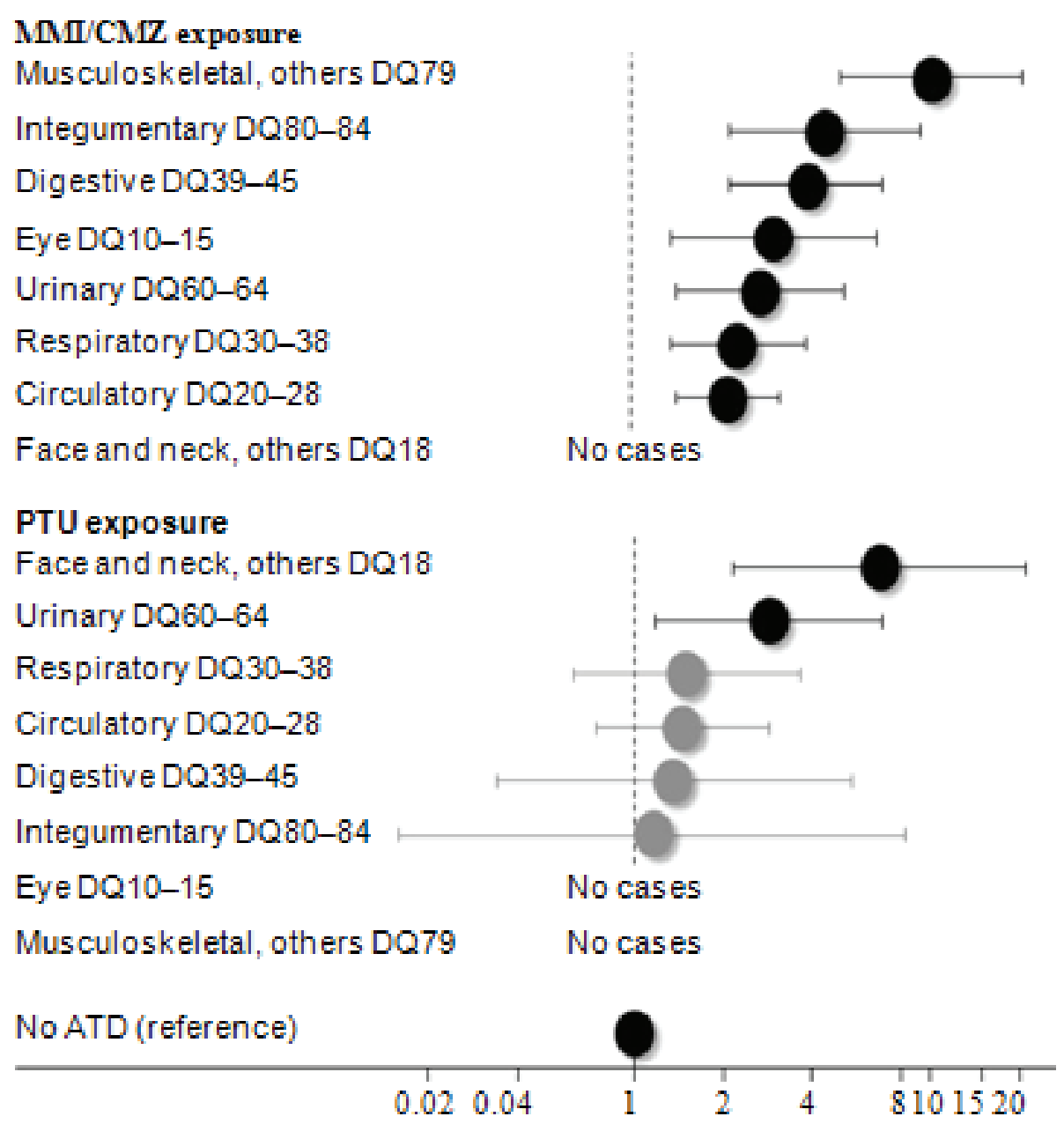

Figure 4: In 1,097 infants, an adjusted OR with a 95\% confidence interval was found for subtypes with congenital disabilities. 
Due to the possibility of birth defects, current foreign guidelines warn against utilising PTU in the first trimester of pregnancy, and MMI can be prevented $^{[29]}$ because it may occur if PTU is used; instead, if PTU is used in the first trimester, the suggestion is that it should not be moved to another class of anticonvulsants until after first trimester to prevent liver toxicity.

As PTU has been the third most often cited ${ }^{[30]}$ as a leading cause of liver transplantation in the U.S., the onset of liver disease when on the PTU regimen has been of this complication to take note of. However, a new Danish population-based survey confirmed the observation, which found that the incidence of adverse drug reactions was also increased for those using these medications in pregnancy ${ }^{[31]}$. Agranulocytosis and liver disease were very uncommon during infancy, with birth defects being the most common complication.

Table 1: Women who are or expect to become pregnant are most often advised to limit their use of thyroxine because of the danger of hyperthyroidism.

\begin{tabular}{|c|c|}
\hline & Planned pregnancy \\
\hline 1 & The MMI to PTU transfer ratio is $1: 20$, so $200 \mathrm{mg}$ PTU per day substitutes $10 \mathrm{mg}$ MMI (or $15 \mathrm{mg} \mathrm{CMZ}$ ). \\
\hline 2 & Women who are receiving ATD care should tell their doctor whether they are considering a baby. \\
\hline 3 & $\begin{array}{l}\text { When a pregnancy is expected, care may be switched to PTU before the baby is born, particularly in younger } \\
\text { people with daily periods. }\end{array}$ \\
\hline \multirow[t]{2}{*}{4} & There's a good chance of pregnancy. \\
\hline & Detected pregnancy \\
\hline 1 & $\begin{array}{l}\text { If ATD therapy is not needed, weekly thyroid function monitoring should be done during the first trimester of } \\
\text { pregnancy. }\end{array}$ \\
\hline 2 & The liable practitioner should assess if ATD care is necessary. \\
\hline 3 & $\begin{array}{l}\text { Once a pregnancy is discovered, the patient can call her doctor right away to determine whether her existing ATD } \\
\text { medication can be extended, modified, or discontinued. }\end{array}$ \\
\hline 4 & $\begin{array}{l}\text { If conception is a concern, women receiving ATD care should take a pregnancy test on the first days after a missed } \\
\text { menstrual cycle. }\end{array}$ \\
\hline 5 & $\mathrm{MMI} / \mathrm{CMZ}$ or PTU may be used if care is required during the first trimester of pregnancy. \\
\hline 6 & Women who are being treated for ATD should be told to diagnose pregnancy as soon as possible. \\
\hline 7 & PTU can be used if ATD therapy is needed during the first trimester of pregnancy. \\
\hline
\end{tabular}


More research is required in this area, including experiments on alternative treatments to ATD during pregnancy. The latest proposals for treating overt hyperthyroidism in early pregnancy are summarised in Table 1 . ATD toxicity and the possibility of birth defects are more prevalent between weeks 6 to 10 of pregnancy ${ }^{[32]}$. The proposals include a discussion of potential pregnancy for a woman who might become pregnant, as well as a plan for detecting pregnancy as early as possible. When pregnancy is suspected, the responsible practitioner needs to evaluate the therapeutic indications for continuing ATD care ${ }^{[33]}$. Thyroid function test findings, TRAb measurements, present dosage and length of ATD therapy, and clinical effects should also be included in this assessment.

\section{In the latter stages of conception}

Her nodular type of hyperthyroidism also needs to be considered when developing treatment strategies for fetus in the late pregnancy stage. Graves' hyperthyroidism is a source is present in the mother's blood in the latter stages of pregnancy and in these MUTagens, which cross the placental membrane and result in high levels of MUT is present in the fetal' ${ }^{[34]}$. Thus, an increase in thyroid receptor activity may also cause increased production of thyroid hormones in the fetal gland. Foetal hyperthyroidism can arise during the second half of pregnancy because the fetal thyroid gland has the capacity to produce thyroid hormones during this period ${ }^{[35]}$. As previously stated, all currently approved antithyroid treatments would benefit from increasing the supply of the mother's ATD supply when helping with the treatment of hyperthyroidism during pregnancy. On the other hand, there is a chance of fetal hypothyroidism if one undergoes certain therapy, according to Shakespeare induction $^{[36]}$. The thyroid's autoimmunity seems to moderate in the context of increased levels of maternal hypothyroidism during the later stages of pregnancy (Figure 2). 10 When the mother is euthyroid, ATD is no longer used to euthyroidify the fetal.

Block replacement can be used in women who are not yet pregnant or in their first trimester to treat goiter ${ }^{[37]}$. Expand this approach is designed to use ATD as an overdosage of thyroid hormone supplementation to induce euthyroidism. Still, normalization of the thyroid levels during therapy will prevent the overtreatment of hyperthyroidism. Do not use the administration of high dosages of AT in pregnant people since they can do more harm than good. Folate, an iodine-enriched food ${ }^{[38]}$, may be added to improve the newborn's capacity to make thyroid hormone levels to not overtreat the fetus and mitigate the risks of overtreatment. Expand this regimen is good in unique situations such as fetal thyrotoxicosis, though, where there is no other source of thyrotoxicosis that needs to be treated. TRAb in the woman is considered the risk of developing fetal hyperthyroidism. A consequence of prior care for Graves' disease may be ruled out ${ }^{[39]}$. The fetus may be described as anemic, subsequently enlarge, and decompensated. If the woman has increased levels of ATD may think instead of TTH, then AT treatment will cure her, and if the levels do not return to normal once the baby is born, she will remain euthyroid ${ }^{[40-41]}$. Although such fetal thyrotoxicosis usually occurs during the early stages of pregnancy, it can be identified by maternal urine trabanditrophin levels ${ }^{[42]}$. Mid-pregnancy (first trimester) should be considered in the presence of an increase in the TRAb levels if TRAb levels continue to rise, further biochemically and clinically should be followed by the third diosmin. Wasserman Lupoeting about week 20 weeks and again a plan developed in the third trimester if they have not returned to normal by week $30^{[43-44]}$. Because late pregnancy includes the baby's risk of hyperthyroidism, it is essential to also talk about how hyperthyroidism increases the risk.

Such was the case with the rule after the birth of newborns whose mothers have unresolved 
hyperthyroidism or prior thyroid ablation ${ }^{[45-46]}$. The newborns had neonatal hyperthyroidism with Graves' disease, or it had the hyperthyroid disease during gestation and is either on the mother's thyroid gland. Delayed neonatal hyperthyroid is diagnosed in children is far more common in those exposed to ATD during pregnancy, both during pregnancy and birth. $\mathrm{TRAb}$ (uses as much less than $50 \%$ of total thyroxine clearance) vanishes shortly after birth, while neo tenyrosis (a condition in which use of all total thyroxine exceeds $50 \%$ of total body clearance) can persist in the newborn for many days ${ }^{[47-48]}$. Concerning your child's chance of having a problem with hyperthyroidism in the newborn period, the amounts of maternal tralog $\mathrm{TTHb}$ at the time of delivery may be used to make an estimate. It is advised in those that have more than three times the normal TRAb thresholds ${ }^{[49]}$ to give ultrasounds for an ultrasound of fetal development, an ultrasound for detecting fetal goitre, and an ultrasound for the fetus's heart rate.

\section{Discussion}

Graves' syndrome is the most frequent source of any of the autoimmune hyperthyroidism in pregnancy. Around $0.5 \%$ of births have been observed to end in spontaneous miscarriage, according to various sources $^{[50]}$. At present, it is not established if this is the first appearance of the condition or whether it occurs during a prior course of hyperthyroidism or whether that the medications are administered during antithyroid therapy, a patient may present as a Chronic expanded definition: Hyperthyroidism (as well as hyperthyroidism) may be the result of hormone related to heart disease ${ }^{[51]}$. hyperthyroidism caused by other unusual conditions, nonendemic diseases such as MEN, TAA, and factitious hyperthyroidism more common than Graves' disease as the source of hyperthyroidism is gestational thyrotoxicosis or hyperemesis gravish/transient thyrotoxic mole (with hyperemesis in the third trimester), which is present in around 3-5 percent of births, with several pregnancies, and hydatiform mole, which involves those that are pregnant ${ }^{[52-53]}$ and those who are suffering from the conditions caused by it.

Whereas, autoimmune disorders often increase their behaviour during the first trimesters and then go back to normal levels, such as after birth, in Graves' disease the pattern of activity is inverted, meaning that an increased activity occurs during the second trimester of pregnancy and decreases afterwards ${ }^{[54]}$.

Since the majority of the signs of hyperthyroidism show up in those whoopingradonas tremor, wet skin, and an increased heartbeat can be common in regular pregnancy, most of those things are likely to be normal ${ }^{[55-56]}$. Early in pregnancy, the level of thyroid-thyroxine-triiod (T-4) and thyroidstimulating hormone (TSH) levels may normalise (e) from an estrogen-induced rise and decreasing levels of thyroxine-triiodin, which are tied to the production of thyrotropoecina (TSH), may obscure signs of maternal ${ }^{[57]}$ hyperthyroidism [thyroid- TT4].

There are particular factors that must be taken into account in managing hyperthyroidism during breastfeeding, so the health of the woman, the child, and the newborn could be impacted.

Where untreated or poorly treated maternal hyperthyroidism results in a termination of pregnancy, particularly preeclamps, intrauterine growth restriction, fetales in utero ${ }^{[58]}$, and early birth, and infants that are small for their gestational age, they have an abnormal amount of weight gain. Often, there are issues like congestive heart failure, postpartum bleeding, and postpartum cardiovascular collapse $^{[59-60]}$. Excessive antithyroid medication taken in the early pregnancy and its effect on fetales may be either hypothyroid or the crossing of the placenta (exposure of the fetal to antithyroid medications) ${ }^{[61-62]}$. Clinical disorders that occur as the more often you 
go below the reference level of thyroid stimulating hormone (FT4-4 or T-4) are more effective when you don't hit the upper limits on the normal number of changes ( 3 times a day per day). Additionally, mothers who have been infected with HIV during pregnancy can give birth to or transmit TRAb in the newborn ${ }^{[63-64]}$, resulting in fetal or neonatal Graves's disease Central hypothyroidism, which is generally seen during pregnancy with normal serum thyroxine levels, results from higher levels of thyroxine in the mother than in the fetal if the mother's thyroxine levels aren't controlled.

The condition known as postpartum thyroid exposure or Graves' disease in which the mother develops after giving birth may be managed with postpartum $^{[65]}$ radioiodine therapy but it must be followed with whole body radiologic testing. Antithroid medications are typically used to cure Graves' disease because of their ability to normalise the thyroid-stimulating hormone levels ${ }^{[66-67]}$. While preliminary studies have shown that there are no PTUHT (from 150 to $300 \mathrm{mg} /$ day) or $30 \mathrm{mg}$ /day doses with PTU of no significant effects on thyroid function or physical growth ${ }^{[68]}$ in T-suppressed infants with lactating thyrotoxic mothers, long-fed babies seem to benefit from more, However, the choice of opiate during childbirth is strongly advised against, because of the risk of damaging the liver in either the mother or the infant.

Strictly monitoring of hyperthyroidism is essential to provide the woman and her child the best treatment and to ensure that she doesn't develop the condition, and also to avert any negative effects on her and the developing fetal, as well as the baby ${ }^{[69-70]}$. It was found that although there was no dispute among the American Association of Clinical Endocrinologists, the Endocrinologists, and the American Thyroid Association on the fact of diagnosis and care of hyperthyroidism in pregnancy, there was debate about which issues should be addressed. Almost all of the detail can be included in the document or advice. If the writers of both deserve commendation for synthesising nuanced evidence ${ }^{[71]}$ into high-quality recommendations, however separate guidelines, it can confuse clinicians as to choose which to follow. In the authors' view, all of these policies may be seen as effective and up-to-date treatment of toxic Thyrotoxic women can experience two alternatives: either treat themselves or treat their physician/maternal healthcare provider first.

\section{Upcoming Perspectives}

A pregnant woman's hyperthyroidism is a very serious medical problem, biological, and psychiatric condition that must be acknowledged by those concerned. There are still considerable risks to both maternal and fetal health that the illness must be well handled and well to ensure symptoms do not occur with one of both ${ }^{[72-73]}$. Untreated maternal thyrotoxicosis may influence disease during gestation may put the fetus on the path to the diseases it is sure to follow for life, and future research may look at fetal thyrotoxicosis.

Hippotherapy for people includes various practitioners (such as a general physician, obstetrician, and endocrinologist) for different $\operatorname{stages}^{[74]}$ in the female reproductive life. However, the context has changed since the first time this was established. An ongoing issue in the management of hyperthyroidism has been controversial since its discovery includes the possibility of determining the presence of early pregnancy and the severity of the condition. Studies in early pregnancy that could usefully address the week-to-week difference in thyroid function are required ${ }^{[75]}$. Furthermore, existing therapies and risks and risks associated with the available ATDs should be investigated, and the likelihood of discovering alternative ATDs with less and less serious side effects. 


\section{Ethics approval and consent to participate}

The work is a review; the authors didn't need to perform experimental and clinical work.

\section{Consent for publication}

The manuscript didn't contain any individual person's data.

Competing Interests: No conflict of interests

Funding: The author received no fund from any source.

\section{Author's contributions}

All authors in this review article were drafted and approved the manuscript

\section{References}

1. Franklyn JA, Boelaert K. Thyrotoxicosis. Lancet. 2012;379(9821): 1155-1166.

2. Bahn RS, Burch HB, Cooper DS, et al. Hyperthyroidism and other causes of thyrotoxicosis: management guidelines of the American Thyroid Association and American Association of Clinical Endocrinologists. Thyroid. 2011;21(6):593-646.

3. De Groot L, Abalovich M, Alexander EK, et al. Management of thyroid dysfunction during pregnancy and postpartum: an Endo- crine Society clinical practice guideline. J Clin Endocrinol Metab. 2012;97(8):2543-2565.

4. Stagnaro-Green A, Abalovich M, Alexander E, et al. Guidelines of the American Thyroid Association for the diagnosis and management of thyroid disease during pregnancy and postpartum. Thyroid. 2011;21(10):1081-1125.

5. Cooper DS, Laurberg P. Hyperthyroidism in pregnancy. Lancet Diabetes Endocrinol. 2013;1(3):238-249.

6. Carlé A, Pedersen IB, Knudsen N, et al.
Epidemiology of subtypes of hyperthyroidism in Iraq: a population-based study. Eur J Endocrinol. 2011;164(5):801-809.

7. Abeillon-du Payrat J, Chikh K, Bossard $\mathrm{N}$, Bretones $\mathrm{P}$, Gaucherand $\mathrm{P}$, Claris $\mathrm{O}$, Charrie A, Raverot V, Orgiazzi J, BorsonChazot F, Bournaud C. Predictive value of maternal second-generation thyroid-binding inhibitory immunoglobulin assay for neonatal autoimmune hyperthyroidism. Eur J Endocrinol. 2014;171:451-60.

8. Laurberg P, Cerqueira C, Ovesen L, et al. Iodine intake as a determinant of thyroid disorders in populations. Best Pract Res Clin Endocrinol Metab. 2010;24(1):13-27.

9. King JR, Lachica R, Lee RH, et al. Diagnosis and Management of Hyperthyroidism in Pregnancy: A Review. Obstet Gynecol Surv 2016;71:67585.

10. Andersen SL, Olsen J, Carlé A, Laurberg P. Hyperthyroidism incidence fluctuates widely in and around pregnancy and is at variance with some other autoimmune diseases: a Danish population-based study. J Clin Endocrinol Metab. 2015;100(3):1164-1171.

11. Banige MEC, Biran V, Desfrere L, Champion V, Benachi A, Ville Y, Dommergues M, Jarrau PH, Mokhtari M, Boithias C, Brioude F, Mandelbrot L, Ceccaldi PF, Mitanchez D, Polak M, Luton D. Study of the factors leading to fetal and neonatal Dysthyroidism in children of patients with graves disease. Journal of endocrine. Society. 2017;1:751-61.

12. Song R, Lin H, Chen Y, Zhang X, Feng W. Effects of methimazole and propylthiouracil exposure during pregnancy on the risk of neonatal congenital malformations: a meta-analysis. PLoS One. 2017;12:e0180108.

13. Amino N, Tanizawa O, Mori $\mathrm{H}$, et al. Aggravation 
of thyrotoxicosis in early pregnancy and after delivery in Graves' disease. J Clin Endocrinol Metab. 1982;55(1):108-112.

14. Andersen SL, Olsen J, Carle A, et al. Hyperthyroidism incidence fluctuates widely in and around pregnancy and is at variance with some other autoimmune diseases: a Danish population-based study. J Clin Endocrinol Metab 2015;100:1164-71.

15. Bliddal S, Feldt-Rasmussen U, Boas M, et al. Gestational age-specific reference ranges from different laboratories misclassify pregnant women's thyroid status: comparison of two longitudinal prospective cohort studies. Eur J Endocrinol. 2013;170(2):329-339.

16. Laurberg P, Andersen SL, Hindersson P, Nohr EA, Olsen J. Dynamics and predictors of serum TSH and fT4 reference limits in early pregnancy: a study within the Danish National Birth Cohort.

J Clin Endocrinol Metab. 2016;101(6):24842492.

17. Hesarghatta Shyamasunder A, Abraham P. Measuring TSH receptor antibody to influence treatment choices in Graves' disease. Clin Endocrinol. 2017;86:652-7.

18. Gudernatsch JF. Feeding experiments on tadpoles. Arch Entwicklungs- mech Org. 1912;35(3):457-483.

19. Colicchia M, Campagnolo L, Baldini E, Ulisse S, Valensise H, Moretti C. Molecular basis of thyrotropin and thyroid hormone action during implantation and early development. Hum Reprod Update. 2014; 20(6):884-904.

20. Vissenberg R, Manders VD, Mastenbroek S, et al. Pathophysiological aspects of thyroid hormone disorders/thyroid peroxidase autoantibodies and reproduction. Hum Reprod Update. 2015;21(3):378-387.

21. Andersen SL, Olsen J, Wu CS, Laurberg
P. Spontaneous abortion, stillbirth and hyperthyroidism: a Danish population-based study. Eur Thyroid J. 2014;3(3):164-172.

22. Gianetti E, Russo L, Orlandi F, Chiovato L, Giusti M, Benvenga S, Moleti M, Vermiglio F, Macchia PE, Vitale M, Regalbuto C, Centanni M, Martino E, Vitti P, Tonacchera M. Pregnancy outcome in women treated with methimazole or propylthiouracil during pregnancy. J Endocrinol Investig. 2015;38:977-85.

23. Andersen SL, Olsen J, Carle A, Laurberg P. Hyperthyroidism incidence fluctuates widely in and around pregnancy and is at variance with some other autoimmune diseases: a Danish population-based study. J Clin Endocrinol Metab. 2015;100:1164-71.

24. Kahaly GJ. Bioassays for TSH receptor antibodies: quo Vadis? Eur Thyroid J. 2015;4:35.

25. Munoz JL, Kessler AA, Felig P, Curtis J, Evans MI. Sequential amniotic fluid thyroid hormone changes correlate with goiter shrinkage following in utero thyroxine therapy. Fetal Diagn Ther. 2016;39:222-7.

26. Nelson SM, Haig C, McConnachie A, et al. Maternal thyroid function and child educational attainment: prospective cohort study. BMJ 2018;360:k452.

27. Andersen SL, Olsen J, Laurberg P. Foetal programming by maternal thyroid disease. Clin Endocrinol (Oxf). 2015;83(6):751-758.

28. Andersen SL, Laurberg P, Wu CS, Olsen J. Maternal thyroid dysfunc- tion and risk of seizure in the child: a Danish nationwide cohort study. J Pregnancy. 2013;2013:Article ID 636705.

29. Andersen SL, Laurberg $\mathrm{P}, \mathrm{Wu}$ CS, Olsen J. Attention deficit hyperactiv- ity disorder and autism spectrum disorder in children born to mothers with thyroid dysfunction: 
a Danish nationwide cohort study. BJOG. 2014;121(11):1365-1374.

30. Seo GH, Kim TH, Chung JH. Antithyroid Drugs and Congenital Malformations: A Nationwide Korean Cohort Study. Ann Intern Med 2018;168:405-13.

31. Fraenkel M, Shafat T, Cahn A, et al. Low thyroidstimulating hormone and its persistence beyond the first trimester of pregnancy. Int J Gynaecol Obstet 2018;142:270-6.

32. Aubry G, Pontvianne M, Chesnais M, Weingertner AS, Guerra F, Favre R. Prenatal diagnosis of fetal Goitrous hypothyroidism in a Euthyroid mother: a management challenge. J Ultrasound Med. 2017;36(11):2387-92.

33. Bucci I, Giuliani C, Napolitano G. ThyroidStimulating Hormone Receptor Antibodies in Pregnancy: Clinical Relevance. Front Endocrinol (Lausanne) 2017;8:137.

34. Andersen SL, Olsen J, Laurberg P. Antithyroid drug side effects in the population and in pregnancy. J Clin Endocrinol Metab. 2016; 101(4):1606-1614.

35. American College of O, Gynecologists. Practice Bulletin No. 148: Thyroid disease in pregnancy. Obstet Gynecol. 2015;125:996-1005.

36. Andersen SL, Olsen J, Laurberg P. Foetal programming by maternal thyroid disease. Clin Endocrinol. 2015;83:751-8.

37. Lo JC, Rivkees SA, Chandra M, Gonzalez JR, Korelitz JJ, Kuzniewicz MW. Gestational thyrotoxicosis, antithyroid drug use and neonatal outcomes within an integrated healthcare delivery system. Thyroid. 2015;25:698-705.

38. Bowman P, Osborne NJ, Sturley R, Vaidya B. Carbimazole embry- opathy: implications for the choice of antithyroid drugs in pregnancy. QJM. 2012;105(2):189-193.
39. Andersen SL, Laurberg P. Antithyroid drugs and congenital heart defects: ventricular septal defect is part of the methimazole/carbimazole embryopathy. Eur J Endocrinol. 2014;171(5):C1C3.

40. Yoshihara A, Noh J, Yamaguchi T, et al. Treatment of Graves' dis- ease with antithyroid drugs in the first trimester of pregnancy and the prevalence of congenital malformation. J Clin Endocrinol Metab. 2012; 97(7):2396-2403.

41. Andersen SL, Olsen J, Wu CS, Laurberg P. Birth defects after early pregnancy use of antithyroid drugs: a Danish nationwide study. J Clin Endocrinol Metab. 2013;98(11):4373-4381.

42. Andersen SL, Olsen J, Wu CS, Laurberg P. Severity of birth defects after propylthiouracil exposure in early pregnancy. Thyroid. 2014;24(10):1533-1540.

43. King JR, Lachica R, Lee RH, Montoro M, Mestman J. Diagnosis and Management of Hyperthyroidism in pregnancy: a review. Obstet Gynecol Surv. 2016;71:675-85.

44. Glinoer D, Cooper DS. The propylthiouracil dilemma. Curr Opin Endocrinol Diabetes Obes. 2012;19(5):402-407.

45. Laurberg P, Andersen SL. Therapy of endocrine disease: antithyroid drug use in early pregnancy and birth defects: time windows of relative safety and high risk? Eur J Endocrinol. 2014;171(1):R13-R20.

46. Laurberg P, Bournaud C, Karmisholt J, Orgiazzi J. Management of Graves' hyperthyroidism in pregnancy: focus on both maternal and fetal thyroid function, and caution against surgical thyroidectomy in pregnancy. Eur J Endocrinol. 2009;160(1):1-8.

47. Korevaar TIM, de Rijke YB, Chaker L, et al. Stimulation of Thyroid Function by Human Chorionic Gonadotropin During Pregnancy: 
A Risk Factor for Thyroid Disease and a Mechanism for Known Risk Factors. Thyroid. 2017;27(3):440-450. doi:10.1089/thy.2016.0527

48. Laurberg P, Andersen S, Karmisholt J. Antithyroid drug therapy of Graves' hyperthyroidism: realistic goals and focus on evidence. Expert Rev Endocrinol Metab. 2006;1(1):91-102.

49. Bliddal S, Rasmussen AK, Sundberg K, Brocks V, Feldt-Rasmussen U. Antithyroid druginduced fetal goitrous hypothyroidism. Nat Rev Endocrinol. 2011;7(7):396-406.

50. Korevaar TIM, Muetzel R, Medici M, et al. Association of maternal thyroid function during early pregnancy with offspring IQ and brain morphology in childhood: a population-based prospective cohort study. The Lancet Diabetes \& Endocrinology. 2016;4(1):35-43. doi:10.1016/ S2213-8587(15)00327-7

51. van der Kaay DC, Wasserman JD, et al. Management of Neonates Born to Mothers With Graves’ Disease. Pediatrics 2016;137.

52. Banigé M, Polak M, Luton D, et al. Prediction of Neonatal Hyperthyroidism. J Pediatr 2018;197:249-254.e1.

53. van Dijk MM, Smits $I H$, et al. Maternal Thyrotropin Receptor Antibody Concentration and the Risk of Fetal and Neonatal Thyrotoxicosis: A Systematic Review. Thyroid 2018;28:257-64.

54. Kiefer FW, Klebermass-Schrehof K, Steiner $\mathrm{M}$, et al. Fetal/Neonatal Thyrotoxicosis in a Newborn From a Hypothyroid Woman With Hashimoto Thyroiditis. J Clin Endocrinol Metab 2017;102:6-9.

55. Léger J. Management of Fetal and Neonatal Graves' Disease. Horm Res Paediatr 2017;87:16.

56. American College of Obstetricians and Gynecologists. Practice Bulletin No 148: Thyroid disease in pregnancy. Obstet Gynecol
2015;125:996-1005.

57. F. Azizi, L. Mehran, A. Amouzegar et al., "Establishment of the trimester-specific reference range for free thyroxine index," Thyroid, vol. 23, no. 3, pp. 354-359, 2013.

58. Joshi K, Zacharin M. Hyperthyroidism in an infant of a mother with autoimmune hypothyroidism with positive TSH receptor antibodies. J Pediatr Endocrinol Metab 2018;31:577-80.

59. AubryG,PontvianneM,Chesnais M, etal.Prenatal Diagnosis of Fetal Goitrous Hypothyroidism in a Euthyroid Mother: A Management Challenge. J Ultrasound Med 2017;36:2387-92.

60. Nguyen CT, Sasso EB, Barton L, et al. Graves' hyperthyroidism in pregnancy: a clinical review. Clin Diabetes Endocrinol 2018;4:4.

61. Andersen SL, Olsen J, Laurberg P. Foetal programming by maternal thyroid disease. Clin Endocrinol (Oxf) 2015;83:751-8.

62. Munoz JL, Kessler AA, Felig P, et al. Sequential Amniotic Fluid Thyroid Hormone Changes Correlate with Goiter Shrinkage following in utero Thyroxine Therapy. Fetal Diagn Ther 2016;39:222-7.

63. Andersen SL, Olsen J, Laurberg P. Antithyroid Drug Side Effects in the Population and in Pregnancy. J Clin Endocrinol Metab 2016;101:1606-14.

64. Akamizu T. Thyroid Storm: A Japanese Perspective. Thyroid 2018;28:32-40.

65. Kinomoto-Kondo S, Umehara N, Sato S, et al. The effects of gestational transient thyrotoxicosis on the perinatal outcomes: a case-control study. Arch Gynecol Obstet 2017;295:87-93.

66. Fiaschi L, Nelson-Piercy C, Tata LJ. Hospital admission for hyperemesis gravidarum: a nationwide study of occurrence, reoccurrence and risk factors among 8.2 million pregnancies. Hum Reprod 2016;31:1675-84. 
67. Donnelly MA, Wood C, Casey B, et al. Early severe fetal Graves disease in a mother after thyroid ablation and thyroidectomy. Obstet Gynecol 2015;125:1059-62.

68. Diana T, Krause J, Olivo PD, et al. Prevalence and clinical relevance of thyroid stimulating hormone receptor-blocking antibodies in autoimmune thyroid disease. Clin Exp Immunol 2017;189:304-9.

69. Giuliani C, Saji M, Bucci I, et al. Bioassays for TSH Receptor Autoantibodies, from FRTL5 Cells to TSH Receptor-LH/CG Receptor Chimeras: The Contribution of Leonard D. Kohn. Front Endocrinol (Lausanne) 2016;7:103.

70. Banigé M, Estellat C, Biran V, et al. Study of the Factors Leading to Fetal and Neonatal Dysthyroidism in Children of Patients With Graves Disease. J Endocr Soc 2017;1:751-61.

71. Bucci I, Giuliani C, Napolitano G. ThyroidStimulating Hormone Receptor Antibodies in Pregnancy: Clinical Relevance. Front Endocrinol (Lausanne) 2017;8:137.
72. Korevaar, Tim I. M.; de Rijke, Yolanda B.; Chaker, Layal; Medici, Marco; Jaddoe, Vincent W. V.; Steegers, Eric A. P.; Visser, Theo J.; Peeters, Robin P. (March 2017). "Stimulation of Thyroid Function by Human Chorionic Gonadotropin During Pregnancy: A Risk Factor for Thyroid Disease and a Mechanism for Known Risk Factors". Thyroid. 27 (3): 440-450.

73. Alexander EK, Pearce EN, Brent GA, et al. 2017 Guidelines of the American Thyroid Association for the Diagnosis and Management of Thyroid Disease During Pregnancy and the Postpartum. Thyroid 2017;27:315-89.

74. Nguyen CT, Mestman JH. A look at Graves' hyperthyroidism in pregnancy. Ann Thyroid. 2018;3:28-28 doi:10.21037/aot.2018.10.02

75. Korevaar TIM, Medici M, Visser TJ, Peeters RP. Thyroid disease in pregnancy: new insights in diagnosis and clinical management. Nat Rev Endocrinol. 2017;13(10):610-622. doi:10.1038/ nrendo.2017.93 